\title{
A curious case of diarrhea
}

\author{
S. De Meulder, F.J. Van de Mierop \\ GZA Sint-Augustinus, gastroenterology, Wilrijk, Belgium.
}

\section{Case presentation}

A 77-year old woman presented with a two-month history of diarrhea. She had a past medical history of infectious colitis dating from 2005, including duodenitis with partial villous atrophy on duodenal biopsy. Celiac serology was negative at the time. Her medication included pantoprazole, aspirin, loop diuretic, statin, levothyroxin, angiotensin-converting-enzyme inhibitor (ACE-inhibitor), benzodiazepine and diltiazem. She reported smoking a few cigarettes a day.

A colonoscopy was performed, which showed spontaneous mucosal tears with bleeding in the right colon (Fig. $1:$ A-B).

What is your diagnosis?

A. Ischemic colitis

B. Collagenous colitis

C. Barotrauma secondary to insufflation during colonoscopy

D. Ulcerative colitis

The correct answer is B. The pathology report confirmed the presence of collagenous colitis (CC). Given the impressive presentation, the patient was started on budesonide, with complete resolution of the symptoms a few weeks later. A follow-up gastroscopy was performed to obtain new duodenal biopsies. These showed no signs of celiac disease. Pantoprazole was stopped, as the gastroscopy was normal, as were the statins. Budesonide was tapered over a 12-week period. She was also advised to quit smoking.

Collagenous colitis (CC) is a condition characterized by chronic watery diarrhea caused by inflammation in the colon. Typically, these patients have a normal looking

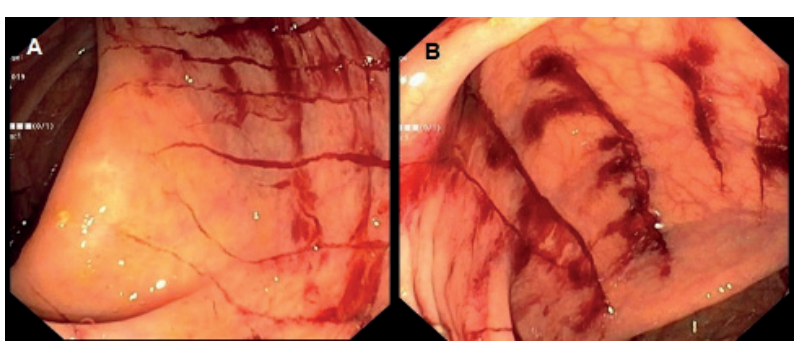

Fig. 1. - A-B : Colonoscopy showing superficial mucosal cracking.

bowel on endoscopy but inflammation on biopsy (1). In rare cases, there is superficial mucosal cracking.

There is a known association with celiac disease. Smoking is a risk factor for the development of CC (2). Certain medication may also play a role in its pathogenesis (2-3).

The first step in the treatment is to exclude provoking medication. In mild disease, antidiarrheal medication may suffice. There is an important role for the use of budesonide in the induction therapy, and if necessary in the maintenance therapy (2-3).

\section{References}

1. KAFIL T, NGUYEN T, PATTON P, MACDONALD J, CHANDE N, MCDONALD J. Interventions for treating collagenous colitis (Review). Cochrane Database Syst. Rev., 2017, (11).

2. MUNCH A, AUST D, BOHR J, BONDERUP O, BANARES FF, HJORTSWANG H, et al. Microscopic colitis : Current status, present and future challenges : Statements of the European Microscopic Colitis Group. J. Crohn's Colitis [Internet], 2012, 6(9) : 932-45.

3. GENTILE N, YEN EF. Prevalence, Pathogenesis, Diagnosis, and Management of Microscopic Colitis. Gut Liver, 2018, 12(3) : 227-35.

Correspondence to : Sofie De Meulder, Herestraat 49, 3000 Leuven.

E-mail : sofie.demeulder@uzleuven.be

Submission date : 22/05/2020

Acceptance date : 09/06/2020 